\title{
Lifestyles and socio-cultural factors among children aged 6-8 years from five Italian towns: the MAPEC_LIFE study cohort
}

Francesco Bagordo ', Antonella De Donno ${ }^{1 *}$, Tiziana Grassi ${ }^{1}$, Marcello Guido ${ }^{1}$, Gabriele Devoti ${ }^{1}$, Elisabetta Ceretti ${ }^{2}$, Claudia Zani ${ }^{2}$, Donatella Feretti ${ }^{2}$, Milena Villarini ${ }^{3}$, Massimo Moretti ${ }^{3}$, Tania Salvatori ${ }^{3}$, Annalaura Carducci ${ }^{4}$, Marco Verani ${ }^{4}$, Beatrice Casini ${ }^{5}$, Sara Bonetta ${ }^{6}$, Elisabetta Carraro ${ }^{6}$, Tiziana Schilirò ${ }^{6}$, Silvia Bonizzoni ${ }^{7}$, Alberto Bonetti ${ }^{8}$, Umberto Gelatti ${ }^{2}$ and MAPEC_LIFE study group

\begin{abstract}
Background: Lifestyles profoundly determine the quality of an individual's health and life since his childhood. Many diseases in adulthood are avoidable if health-risk behaviors are identified and improved at an early stage of life. The aim of the present research was to characterize a cohort of children aged 6-8 years selected in order to perform an epidemiological molecular study (the MAPEC_LIFE study), investigate lifestyles of the children that could have effect on their health status, and assess possible association between lifestyles and socio-cultural factors.

Methods: A questionnaire composed of 148 questions was administered in two different seasons to parents of children attending 18 primary schools in five Italian cities (Torino, Brescia, Pisa, Perugia and Lecce) to obtain information regarding the criteria for exclusion from the study, demographic, anthropometric and health information on the children, as well as some aspects on their lifestyles and parental characteristics. The results were analyzed in order to assess the frequency of specific conditions among the different seasons and cities and the association between lifestyles and socio-economic factors.

Results: The final cohort was composed of 1,164 children (50.9 boys, 95.4\% born in Italy). Frequency of some factors appeared different in terms of the survey season (physical activity in the open air, the ways of cooking certain foods) and among the various cities (parents' level of education and rate of employment, sport, traffic near the home, type of heating, exposure to passive smoking, ways of cooking certain foods). Exposure to passive smoking and cooking fumes, obesity, residence in areas with heavy traffic, frequency of outdoor play and consumption of barbecued and fried foods were higher among children living in families with low educational and/or occupational level while children doing sports and consuming toasted bread were more frequent in families with high socio-economic level.
\end{abstract}

Conclusions: The socio-economic level seems to affect the lifestyles of children enrolled in the study including those that could cause health effects. Many factors are linked to the geographical area and may depend on environmental, cultural and social aspects of the city of residence.

Keywords: Children, Lifestyles, Exposure, Air pollution, Questionnaire, MAPEC_LIFE Study

\footnotetext{
* Correspondence: antonella.dedonno@unisalento.it

'Department of Biological and Environmental Science and Technology,

University of Salento, Via Prov.le Lecce-Monteroni, 73100 Lecce, Italy

Full list of author information is available at the end of the article
}

(c) The Author(s). 2017 Open Access This article is distributed under the terms of the Creative Commons Attribution 4.0 International License (http://creativecommons.org/licenses/by/4.0/), which permits unrestricted use, distribution, and reproduction in any medium, provided you give appropriate credit to the original author(s) and the source, provide a link to the Creative Commons license, and indicate if changes were made. The Creative Commons Public Domain Dedication waiver (http://creativecommons.org/publicdomain/zero/1.0/) applies to the data made available in this article, unless otherwise stated. 


\section{Background}

According to the World Health Organization definition, lifestyles are ways "of living based on identifiable patterns of behaviour which are determined by the interplay between an individual's personal characteristics, social interactions, and socioeconomic and environmental living conditions" [1]. They represent a group of factors that profoundly determine the quality of an individual's health and life [2].

Lifestyles include living conditions editable since they are determined by the choices made by each individual in the course of its existence [3] and can be divided into health-risk behaviors and health-promoting behaviors. Health-risk behaviors (e.g., smoking habit, alcohol use, sedentary lifestyle, high-calorie diet, living in polluted areas) are activities or conditions that increase a person's vulnerability or susceptibility to negative health outcomes (cancer, obesity, diabetes, cardiovascular diseases) [4]. In contrast, health-promoting behaviors (physical activity, proper nutrition, etc.) entail an increase in the psycho-physical well-being which prevent morbidity and premature mortality [5-7]. The socio-economic context, namely that resulting from the interaction of several factors such as culture, education, income, family structure, home and work environment, can affect many behavioral and decision-making aspects playing a role on health literacy, or on the availability of goods and services [8].

Life quality and health in adulthood often depends on the living habits adopted since early years. Many studies revealed that health-risk beaviours in childhood may have short-term consequences [9] and could be carried into adulthood determining also long-term consequences $[9,10]$, as well as being a substantial economic burden [11-13]. Therefore, many diseases in adulthood are avoidable if health-risk behaviors are identified and improved at an early stage of life [7].

The purpose of the present research was to a) characterize a cohort of children aged 6-8 years selected in order to perform an epidemiological molecular study in five Italian cities (the MAPEC_LIFE - Monitoring Air Pollution Effects on Children for Supporting Public Health Policy - study), b) investigate lifestyles of the children that could have effect on their health status, and c) assess possible association between lifestyles and sociocultural factors.

\section{Methods}

\section{Study design}

This study was included in the MAPEC_LIFE project (LIFE12 ENV/IT/000614) [14], a multicenter cohort study funded by the European Union's LIFE+ Programme which aims to assess the association between concentrations of monitored atmospheric pollutants and early biological effects on children aged 6-8 years living in areas with varying levels of air pollution and to build a model for estimating global genotoxic risk that can be used to support public health policy.

In order to accurately correlate biological effects with the concentration of atmospheric pollutants, the parents of children participating in the MAPEC_LIFE study were asked in two different seasons to fill in a pre-validated questionnaire [15] to assess lifestyles and exposure factors linked to the home context that could have a confounding effect on the measured responses.

\section{Cities involved in the study}

The study was conducted in five Italian cities (Fig. 1), differing in geographical, environmental, demographic and socio-economic terms.

Torino (TO) $(890,529$ inhabitants [16]) is situated in the north-west of the Pianura Padana, the Plain of the river Po, in a metropolitan area with more than two million inhabitants which is one of the most important economic and industrial sites in Italy [17]. The city's core and the surrounding urban area pay the price of economic development in terms of exposure to high levels of air pollution $[18,19]$. Torino is the coldest of the cities included in the study [20], with an average annual temperature in the last 10 years of $13.2^{\circ} \mathrm{C}$ (Torino-Caselle Weather Station).

Brescia (BS) (about 200,000 inhabitants) is part of an extensive metropolitan area, highly industrialized, with a high level of motor vehicle traffic. It is situated in the high Pianura Padana, one of the most highly polluted areas in Europe $[21,22]$ and has a humid subtropical climate [23]. It is characterized by one of the highest rates of immigration in Lombardia and the highest number of foreign residents. A recent study [24] includes it with Pisa among cities characterized by high levels of economic development, well-being and cultural activity.

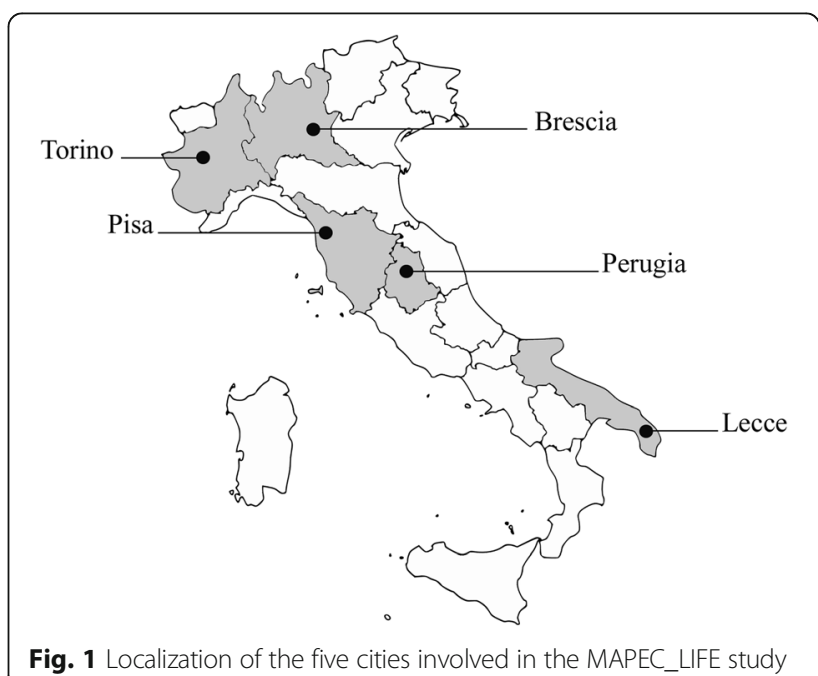


Pisa (PI), with just under 90,000 inhabitants, is the smallest of the cities in the study. It lies a few kilometers from the mouth of the river Arno in a flat area that hosts a large industrial estate. The climate is affected by the vicinity of the sea, which tends to mitigate both the rigors of winter and the heat of summer. The social fabric is influenced by a large number of foreign residents and the presence of many university students.

Perugia (PG) (about 166,000 inhabitants) is in central Italy at an altitude of more than $400 \mathrm{~m}$ above the sea level. It has a temperate climate with an average annual temperature in the last decade of just over $14{ }^{\circ} \mathrm{C}$. The economy is mainly based on the tertiary sector while the industrial sector is composed above all of textiles and food processing. In PG too, a large part of the population is accounted for by foreigners and students, although the old age index (percentage ratio between population aged 65 years and over and population aged $0-14$ years) is much higher (163.5) than the national average.

Lecce (LE) has just over 90,000 inhabitants and is situated in south-east Italy, in the center of the Salento peninsula. It has a Mediterranean climate, with mild winters and hot humid summers. Like PE it is a city with a solid but largely static economy [24], based essentially on food processing, handicrafts, tourism and services, and is characterized by the tendency towards an ageing population.

\section{Recruitment of the children}

Recruitment was conducted randomly among the children attending first, second and third year classes of 18 primary schools located in the five cities of the study (selected in order to recruit at least 200 children from at least three schools per city, located in the urban area and in different neighborhoods, far from point sources of contamination, and free from radioactive indoor pollution) in accordance with a protocol [14] shared by the Research Units of the Universities of Brescia, Salento (LE), Perugia, Pisa and Torino. Participation in the study was on a voluntary basis after inviting the parents of all children attending these classes by distribution of a study parcel which contained a) a fact sheet informing the children's parents about the study, its objectives and methods and; b) the informed consent form. The parents who had agreed to participate in the study gave the approval to the recruitment of their children by signing the consent form.

\section{Questionnaire administration}

The parents of children participating in the study were asked to fill in a previously validated questionnaire [15], composed of 148 questions, subdivided into various sections: criteria for exclusion from the study (age below
6 years or equal/above nine, residence in cities other than those involved in the study, the presence of serious illness, exposure to radiotherapy or chemotherapy in the 12 months preceding the investigation, exposure to radiographic testing in the month preceding the investigation, use of dental braces); the child's personal information (gender, date and nation of birth); the child's weight and height; information on the child's health status (respiratory problems beyond the common cold and consumption of medicines in addition to common remedies such as antibiotics, antipyretics and antiinflammatory agents); domestic environment (intensity of traffic near the home, including heavy goods vehicles, fuel used for heating and cooking, presence of gas boilers, stoves and fireplaces inside the dwelling, presence of smokers inside the dwelling, use of solvents for hobbies, i.e., paint thinner, white spirit, acetone, turpentine, toluene, etc.); information on the child's lifestyle (exercise, consumption of dishes cooked in certain ways); parents' characteristics (nation of birth, level of education, occupation, smoking habits); information on the child's eating habits. All the questions were of the "closed answer" type.

The parents of each child filled in the questionnaire twice in two different seasons (Season I, winter 20142015, and Season II, late spring 2015), directly on a specially created web platform or in paper format. In the latter case the completed questionnaires were returned to the teachers and uploaded to the web platform by the personnel of the various Research Units. The software supporting the web platform assigned an alphanumeric identification code to each questionnaire and related data were transferred automatically to spreadsheets for processing.

\section{Sample size}

The final cohort was composed of all children whose parents completed valid questionnaires in both seasons. In total, 1164 children, $3.1 \%$ of the total children aged 6-8 years living in the cities involved in the study, were enrolled.

\section{Data processing}

The exact age at testing was measured by calculating the time interval between the date of birth given on the questionnaire and the date of filling the questionnaire. The data for weight and height given by the parents were used to calculate the children's body mass index (BMI) (weight $[\mathrm{kg}] /$ height $[\mathrm{m}]$ squared), which was used in turn to assess whether the child was underweight (UW), of normal weight (NW), overweight (OW) or obese $(\mathrm{OB})$. In accordance with the indications of the International Obesity Task Force (IOTF), OW and OB were defined with reference to the BMI threshold values 
for boys and girls aged 2-18 years, calculated by Cole et al. [25] on the basis of adult values (overweight = $25 \mathrm{~kg} / \mathrm{m}^{2}$; obesity $\left.=30 \mathrm{~kg} / \mathrm{m}^{2}\right)$. The cut-off for the UW category was set at the "- $2 \mathrm{z}$-score" on the basis of the BMI threshold values set out in Cole et al. [26]. The data thus obtained were statistically processed using MedCalc Software version 12.3 (MedCalc Software bvba, Ostend, Belgium).

The answers in the questionnaires were analyzed in order to assess the average values ( \pm standard deviation) of quantitative variables (i.e., age, height, weight, BMI, use of stoves and fireplaces), and the frequency of children with specific characteristics in the two seasons and the five cities participating in the study. Quantitative data were compared by one-way ANOVA, and frequencies by the chi-squared test. Differences were considered significant at $p<0.05$.

In addition, the association between certain behavioral factors (e.g., exposure to passive smoking, living in areas with heavy traffic, obesity, physical activity, consumption of foods cooked by risky methods), and socio-economic level of the children's families was assessed by chi-squared test taking into account the overall level of parents' education and father's employment. The parents' level of education was calculated as total years of schooling, depending on the mother's and father's educational level reported in the questionnaire. According to the Italian school system, we assigned 0 years when parents reported not having any degree; 5 years to primary school certificate; 3 years to junior high school diploma; 5 years to high school diploma; and 5 years to graduate. The employment level of the father was divided into four categories: level I (businessmen, managers, professionals); level II (office worker); level III (manual worker, craftsman); level IV (unemployed).

\section{Ethical aspects}

The study was approved by the competent Ethical Committees in each involved city. All the data were gathered and analyzed in accordance with Italian Legislative Decree 196 of 30/6/2003 ("protection of personal data") and subsequent additions, for the purposes of research.

\section{Results}

\section{Recruitment}

The results of the recruitment and questionnaire administration activities are illustrated in Table 1. A total of 3,144 parcels were distributed to parents of children attending first, second and third year classes in selected schools in the five towns; 1,767 (56.2\%) correctly compiled consent forms were gathered and the same number of questionnaires were given during the first season to the parents who decided to participate. Overall, 1,356 questionnaires $(76.7 \%)$ were valid, after excluding those that were either incomplete $(n=265)$ or did not meet the criteria for inclusion $(n=146)$.

In the second season 1,318 questionnaires were handed in. Of these, 1,164 (final cohort) were found to be valid, with an average loss with respect to the first season of $14.2 \%$, ranging from $10.4 \%$ in LE to $20.6 \%$ in PG.

\section{Characteristics of the recruited children}

Children included in the final cohort (Table 2) were $50.9 \%$ boys and $95.4 \%$ born in Italy. Their mean age at the time of recruitment was $7.34 \pm 0.87$ years while the average BMI was $16.5 \pm 2.6 \mathrm{~kg} / \mathrm{m}^{2}$. Regarding their weight status large number of children were overweight (12.5\% in the Season I and $13.7 \%$ in Season II) or obese (16.2-14.8\%). No significant difference between the two surveys was recorded, although during the second season there was a significantly diverse distribution $(p<0.05)$ of normal-weight children among the

Table 1 Results of recruitment and questionnaire administration activities

\begin{tabular}{|c|c|c|c|c|c|c|}
\hline & BS & LE & PG & $\mathrm{PI}$ & TO & TOTAL \\
\hline Selected schools (n) & 4 & 3 & 4 & 4 & 3 & 18 \\
\hline Distributed parcels (n) & 600 & 750 & 711 & 527 & 556 & 3144 \\
\hline \multicolumn{7}{|l|}{ Season I } \\
\hline Informed consents/distributed questionnaires (n) & 406 & 343 & 416 & 282 & 320 & 1767 \\
\hline Completed questionnaires (n) & 325 & 284 & 350 & 268 & 275 & 1502 \\
\hline Valid questionnaires (n) & 289 & 270 & 296 & 246 & 255 & 1356 \\
\hline \multicolumn{7}{|l|}{ Season II } \\
\hline Distributed questionnaires ( $\mathrm{n}$ ) & 283 & 266 & 276 & 242 & 251 & 1318 \\
\hline Completed questionnaires ( $n$ ) & 265 & 249 & 249 & 219 & 237 & 1219 \\
\hline Valid questionnaires $(n)^{a}$ & 250 & 242 & 235 & 210 & 227 & 1164 \\
\hline
\end{tabular}


Table 2 Demographic and anthropometric variables, health status and physical activity among children participating in the study

\begin{tabular}{|c|c|c|c|c|c|c|c|}
\hline & BS & LE & $P G$ & $\mathrm{PI}$ & TO & MAPEC_LIFE cohort & $P$-value \\
\hline Males (\%) & 47.2 & 49.2 & 58.3 & 46.2 & 53.3 & 50.9 & $0.057^{\mathrm{a}}$ \\
\hline Born in Italy $(\%)$ & 94.4 & 97.9 & 96.2 & 93.8 & 94.7 & 95.4 & $0.204^{a}$ \\
\hline \multicolumn{8}{|l|}{ Age (years) } \\
\hline Season 1 & 7.42 & 7.38 & 7.36 & 7.15 & 7.33 & 7.34 & $0.051^{\mathrm{b}}$ \\
\hline Season 11 & 7.76 & 7.53 & 7.66 & 7.53 & 7.67 & 7.63 & $0.052^{b}$ \\
\hline \multicolumn{8}{|l|}{ Height (cm) } \\
\hline Season 1 & 124.8 & 125.4 & 125.1 & 123.6 & 125.0 & 124.8 & $0.183^{\mathrm{b}}$ \\
\hline Season II & 127.1 & 126.7 & 126.8 & 126.1 & 126.6 & 126.7 & $0.756^{b}$ \\
\hline \multicolumn{8}{|l|}{ Weight (kg) } \\
\hline Season 1 & 25.5 & 26.4 & 26.5 & 25.5 & 25.7 & 25.9 & $0.102^{\mathrm{b}}$ \\
\hline Season II & 26.5 & 26.9 & 27.1 & 26.7 & 26.5 & 26.7 & $0.725^{\mathrm{b}}$ \\
\hline \multicolumn{8}{|l|}{ BMI $\left(\mathrm{kg} / \mathrm{m}^{\mathrm{b}}\right)$} \\
\hline Season 1 & 16.3 & 16.7 & 16.8 & 16.6 & 16.3 & 16.5 & $0.076^{b}$ \\
\hline Season II & 16.2 & 16.6 & 16.7 & 16.7 & 16.5 & 16.6 & $0.200^{b}$ \\
\hline \multicolumn{8}{|l|}{ UW $(\%)^{c}$} \\
\hline Season 1 & 3.6 & 4.1 & 3.8 & 2.9 & 2.2 & 3.4 & $0.781^{\mathrm{a}}$ \\
\hline Season II & 2.4 & 4.5 & 1.3 & 3.3 & 3.5 & 3.0 & $0.290^{\mathrm{a}}$ \\
\hline \multicolumn{8}{|l|}{ NW (\%) } \\
\hline Season 1 & 70.8 & 66.9 & 66.0 & 63.3 & 72.2 & 68.0 & $0.244^{\mathrm{a}}$ \\
\hline Season II & 75.6 & 64.5 & 68.9 & 62.9 & 69.6 & 68.5 & $0.028^{\mathrm{a}}$ \\
\hline \multicolumn{8}{|l|}{ OW (\%) ${ }^{d}$} \\
\hline Season 1 & 13.2 & 13.2 & 11.9 & 15.7 & 8.8 & 12.5 & $0.278^{\mathrm{a}}$ \\
\hline Season 11 & 10.4 & 15.7 & 14.0 & 16.2 & 12.8 & 13.7 & $0.355^{\mathrm{a}}$ \\
\hline \multicolumn{8}{|l|}{$\mathrm{OB}(\%)^{\mathrm{e}}$} \\
\hline Season 1 & 12.4 & 15.7 & 18.3 & 18.1 & 16.7 & 16.2 & $0.396^{\mathrm{a}}$ \\
\hline Season 11 & 11.6 & 15.3 & 15.7 & 17.6 & 14.1 & 14.8 & $0.454^{\mathrm{a}}$ \\
\hline \multicolumn{8}{|c|}{ Respiratory problems $(\%)^{\mathrm{f}}$} \\
\hline Season 1 & 17.2 & 15.7 & 16.2 & 15.7 & 18.1 & 16.6 & $0.951^{\mathrm{a}}$ \\
\hline Season $\|$ & 19.2 & 14.5 & 14.9 & 15.7 & 15.4 & 16.0 & $0.624^{\mathrm{a}}$ \\
\hline \multicolumn{8}{|c|}{ Consumption of medicines $(\%)^{9}$} \\
\hline Season 1 & 5.6 & 3.3 & 7.7 & 4.8 & 4.0 & 5.1 & $0.231^{\mathrm{a}}$ \\
\hline Season $\|$ & 4.8 & 5.4 & 6.0 & 4.8 & 4.8 & 5.2 & $0.973^{\mathrm{a}}$ \\
\hline \multicolumn{8}{|c|}{ Sport (equal or above 3 times/week) (\%) } \\
\hline Season 1 & 42.0 & 57.0 & 44.7 & 42.4 & 37.4 & 44.8 & $<0.001^{\circ}$ \\
\hline Season $\|$ & 44.8 & 57.9 & 47.7 & 47.6 & 40.1 & 47.7 & $0.003^{\mathrm{a}}$ \\
\hline \multicolumn{8}{|c|}{ Outdoor sports (\%) } \\
\hline Season 1 & 31.6 & 26.4 & 31.9 & 27.1 & 23.8 & 28.3 & $0.224^{\mathrm{a}}$ \\
\hline Season II & $41.6^{*}$ & $35.5^{*}$ & $40.9^{*}$ & $36.7^{*}$ & 28.2 & $36.7^{*}$ & $0.021^{\mathrm{a}}$ \\
\hline \multicolumn{8}{|c|}{ Swimming (indoor) (\%) } \\
\hline Season 1 & 3.6 & 13.6 & 3.4 & 5.7 & 3.5 & 6.0 & $<0.001^{\circ}$ \\
\hline Season II & 5.2 & 12.0 & 8.5 & 5.7 & 4.4 & 7.2 & $0.008^{\mathrm{a}}$ \\
\hline \multicolumn{8}{|c|}{ Outdoor play (above 1 h/day) (\%) } \\
\hline Season 1 & 35.6 & 25.6 & 28.5 & 40.0 & 36.1 & 33.0 & $0.003^{\mathrm{a}}$ \\
\hline Season $\|$ & $72.0^{*}$ & $59.9^{*}$ & $66.4^{*}$ & $80.0^{*}$ & $74.4^{*}$ & $70.3^{*}$ & $<0.001^{\circ}$ \\
\hline
\end{tabular}

${ }^{a}$ significance level by chi-squared test among frequencies in the various cities

bignificance level by one-way ANOVA among average values in the various cities

"BMI cut-off point for age and sex set at "-2z score" according to Cole et al. [26]

${ }^{\mathrm{d}}$ Include children whose BMI is comprised between the 85th and 95th percentiles specific for age and sex according to Cole et al. [25]

e Include children whose BMI is above the 95th percentile specific for age and sex according to Cole et al. [25]

fbeyond the common cold

$g_{\text {in }}$ addition to common remedies such as antibiotics, antipyretics and anti-inflammatory agents

${ }^{*} p$-value $<0.05$ by chi-squared test between frequencies in the two seasons 
various cities, with the highest frequency seen in BS (75.6\%), followed by TO (69.6\%), PG (68.9\%), LE (64.5\%) and PI (62.9\%).

$16.6 \%$ of the children in season I and $16.0 \%$ in season II suffered from respiratory problems beyond the common cold with significant differences between the cities regarding the incidence of catarrh (Fig. 2) in winter, the highest values in TO (9.3\%) and BS (9.2\%) and the lowest in LE (4.5\%) and PI (3.3\%). The average rate of use of medicines in addition to common remedies such as antibiotics, antipyretics and anti-inflammatory agents in the 6 months before sampling was 5.1\% in season I and 5.2\% in season II.

Concerning physical activity, $44.8 \%$ of the children did sport three or more times a week in season I and $47.7 \%$ in season II. The percentages of children doing sport in the open air increased significantly $(p<0.05)$ from the first season (28.3\%) to the second season (36.7\%), as did the percentages of children playing outdoors for more than $1 \mathrm{~h}$ a day $(33.0 \%$ in the first season, $70.3 \%$ in the second). Significantly different frequencies among the cities were recorded.

\section{Characteristics of the parents}

The parents of the recruited children exhibited significantly different characteristics $(p<0.05)$ in terms of gender and city (Table 3). $84.7 \%$ of the mothers and $88.1 \%$ of the fathers were born in Italy with the highest values seen in LE (92.4\% of mothers and $95.7 \%$ of fathers) and the lowest in PI (77.4\% of mothers and $82.9 \%$ of fathers). The level of education is highest among the parents of PG, where $91.1 \%$ of mothers and $85.0 \%$ of fathers have at least a high-school leaving certificate (in BS only $78.4 \%$ of mothers and $68.8 \%$ of fathers). Overall, the mothers were more likely than the fathers to have this level of education (83.7 vs. $76.2 \%$ ). In contrast, the rate of employment is higher among the fathers (73.3 vs. $89.2 \%)$. In addition, the fathers are more likely to be smokers $(27.5 \%)$ than the mothers $(19.2 \%)$, while TO had the highest frequency of smoking parents $(36.6 \%$ of fathers and $26.0 \%$ of mothers) and PG the lowest (20.6\% of fathers and $13.2 \%$ of mothers).

\section{Domestic environment}

The type of fuel used for domestic heating varies significantly among the various cities (Table 4). In BS and TO, the presence of district heating model is significant, while in the other cities natural gas is prevalent. Stoves are present in $7.3 \%$ of the dwellings. In most cases they run on wood or pellets (3.8\%) and to a lesser extent on fossil fuels $(2.4 \%)$ or electricity (1.1\%). Open hearths are found in $23.7 \%$ of the dwellings, with a greater frequency in LE (37.2\%) and a lower frequency in TO (7.0\%). In the latter city, there is a greater frequency of gas boilers installed inside the apartment (18.5\%). The main fuel used for cooking is natural gas (methane) in all the cities involved in the study. However, significant differences were found regarding the use of electricity, which is most frequent in BS (21.1\%).

As shown in Table 5, TO had the highest percentage of children resident in areas judged to be of high traffic intensity by parents in both the first (53.7\%) and second (60.4\%) seasons. TO also had the largest number of children exposed to heavy vehicle traffic $(17.6 \%$ in both seasons). Wood-burning stoves are most frequently used in the homes of PG (15.3 days/month in the first season and 13.3 days/month in the second season). Openhearth fires were used most frequently in LE in the first season (7.3 days/month) and in TO in the second season (3.3 days/month). The habit of smoking in the home by

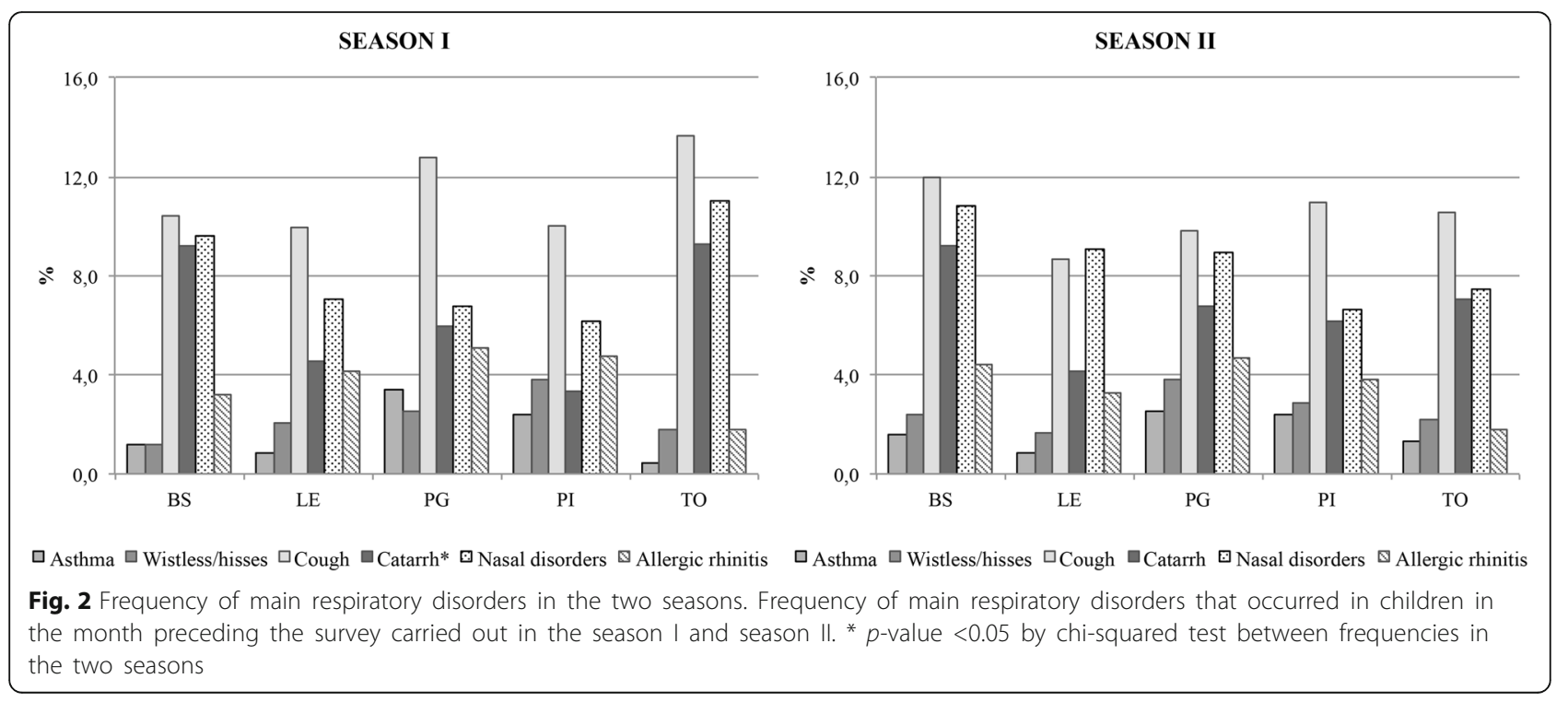


Table 3 Prevalence of variables regarding parents of children included in the MAPEC_LIFE cohort

\begin{tabular}{|c|c|c|c|c|c|c|c|}
\hline & BS & LE & $P G$ & $\mathrm{Pl}$ & TO & mean & $P$-value ${ }^{a}$ \\
\hline \multicolumn{8}{|c|}{ Born in Italy (\%) } \\
\hline Mother & 83.4 & 92.4 & 87.2 & 77.4 & 82.2 & 84.7 & $<0.001$ \\
\hline Father & 86.6 & 95.7 & 90.6 & 82.9 & 84.1 & 88.1 & $<0.001$ \\
\hline \multicolumn{8}{|c|}{ High-school education or greater (\%) } \\
\hline Mother & 78.4 & 85.1 & 91.1 & 85.0 & 79.3 & 83.7 & $<0,001$ \\
\hline Father & 68.8 & 78.2 & 85.0 & 72.8 & 76.4 & 76.2 & $<0,001$ \\
\hline \multicolumn{8}{|c|}{ Employment rate (\%) } \\
\hline Mother & 76.0 & 61.6 & 77.4 & 74.6 & 77.5 & 73.3 & $<0.001$ \\
\hline Father & 93.9 & 83.8 & 91.8 & 86.0 & 90.1 & 89.2 & 0.002 \\
\hline \multicolumn{8}{|c|}{ Smoking habits (\%) } \\
\hline Mother & 16.6 & 20.2 & 13.2 & 20.5 & 26.0 & 19.2 & $<0.001$ \\
\hline Father & 22.1 & 28.6 & 20.6 & 30.4 & 36.6 & 27.5 & $<0.001$ \\
\hline \multicolumn{8}{|c|}{ Smoking parents (\%) } \\
\hline Both & 8.7 & 12.0 & 6.5 & 11.6 & 20.5 & 11.8 & $<0.001$ \\
\hline One only & 21.4 & 24.9 & 20.9 & 28.0 & 21.6 & 23.3 & 0.058 \\
\hline Neither & 69.9 & 63.1 & 72.7 & 60.4 & 57.9 & 65.0 & $<0.001$ \\
\hline
\end{tabular}

${ }^{\mathrm{a}}$ significance level by chi-squared test among frequencies in the various cities

one or more persons was recorded in $13.3 \%$ of cases in the first season and $13.5 \%$ in the second, while the presence of the child in closed rooms with smokers was declared by $3.5 \%$ of parents in the first season and $2.8 \%$ in the second. The presence of the child in the kitchen during food cooking was recorded in $17.1 \%$ of cases during

Table 4 Prevalence of different systems for heating and cooking food in the dwellings of enrolled children

\begin{tabular}{lcllllll}
\hline & BS & LE & PG & PI & TO & mean & $P$-value \\
\hline Fuel used for heating (\%) & & & & & & \\
Wood/Pellet & 6.9 & 7.2 & 12.4 & 1.4 & 1.5 & 6.2 & $<0.001$ \\
Diesel/Kerosene & 0.6 & 1.4 & 5.1 & 2.6 & 10.1 & 3.9 & $<0.001$ \\
Gas & 30.2 & 83.5 & 78.3 & 92.4 & 57.7 & 67.7 & $<0.001$ \\
Electricity & 3.3 & 8.0 & 2.7 & 2.9 & 0.9 & 3.6 & $<0.001$ \\
District heating & 59.1 & 0 & 1.1 & 0 & 29.8 & 18.5 & $<0.001$ \\
Stoves (\%) & & & & & & & \\
Wood/Pellet & 6.0 & 2.5 & 7.2 & 2.4 & 0.4 & 3.8 & $<0.001$ \\
Gas/kerosene & 1.2 & 5.0 & 1.3 & 3.3 & 1.3 & 2.4 & 0.220 \\
Electricity & 0.4 & 2.1 & 1.3 & 1.0 & 0.9 & 1.1 & 0.500 \\
Fireplaces (\%) & 23.6 & 37.2 & 34.9 & 13.8 & 7.0 & 23.7 & $<0.001$ \\
Gas boiler (\%) & 11.2 & 3.3 & 8.9 & 17.1 & 18.5 & 11.6 & $<0.001$ \\
Fuel used for cooking (\%) & & & & & & \\
Electricity/Induction & 21.1 & 13.6 & 8.0 & 9.7 & 5.4 & 11.7 & $<0.001$ \\
Gas & 78.2 & 85.7 & 89.2 & 90.3 & 94.6 & 87.4 & $<0.001$ \\
Wood/Charcoal & 0.8 & 0.8 & 2.8 & 0 & 0 & 0.9 & 0.005 \\
\hline
\end{tabular}

${ }^{a}$ significance level by chi-squared test among frequencies in the various cities
Table 5 Prevalence of exposure factors linked to the home context in the study cohort

\begin{tabular}{|c|c|c|c|c|c|c|c|}
\hline & BS & LE & PG & $\mathrm{Pl}$ & $\mathrm{TO}$ & mean & $P$-value \\
\hline \multicolumn{8}{|c|}{ Residence in areas with heavy traffic (\%) } \\
\hline Season 1 & 35.6 & 24.8 & 33.6 & 22.9 & 53.7 & 34.2 & $<0.001^{\mathrm{a}}$ \\
\hline Season $\|$ & 42.4 & 29.3 & 36.2 & 29.0 & 60.4 & 39.5 & $<0.001^{\mathrm{a}}$ \\
\hline \multicolumn{8}{|c|}{ Residence in areas with heavy traffic of heavy vehicles (\%) } \\
\hline Season I & 14.8 & 7.0 & 6.0 & 6.2 & 17.6 & 10.4 & $<0.001^{\mathrm{a}}$ \\
\hline Season $\|$ & 11.6 & 5.4 & 7.7 & 5.2 & 17.6 & 9.5 & $<0.001^{\mathrm{a}}$ \\
\hline \multicolumn{8}{|c|}{ Use of stoves $(\mathrm{d} / \mathrm{m})$} \\
\hline Season 1 & 8.2 & 15.3 & 15.3 & 7.0 & 6.5 & 11.7 & $0.052^{b}$ \\
\hline Season II & 11.7 & 7.1 & 13.3 & 3.0 & 7.8 & 9.2 & $0.081^{b}$ \\
\hline \multicolumn{8}{|c|}{ Use of fireplaces $(\mathrm{d} / \mathrm{m})$} \\
\hline Season I & 3.1 & 7.3 & 6.0 & 2.3 & 1.8 & 5.2 & $0.040^{b}$ \\
\hline Season II & 1.3 & 3.1 & 2.3 & 0.6 & 3.3 & 2.2 & $0.221^{b}$ \\
\hline
\end{tabular}

Presence of smokers inside the dwelling (\%)

$\begin{array}{llllllll}\text { Season I } & 12.8 & 14.0 & 11.9 & 13.8 & 12.3 & 13.3 & 0.952^{\mathrm{a}}\end{array}$

$\begin{array}{llllllll}\text { Season II } & 12.0 & 12.8 & 11.9 & 19.0 & 12.3 & 13.5 & 0.142^{\mathrm{a}}\end{array}$

Staying in closed rooms with smokers (\%)

$\begin{array}{llllllll}\text { Season I } & 4.0 & 3.7 & 3.0 & 3.3 & 3.5 & 3.5 & 0.981^{\mathrm{a}} \\ \text { Season II } & 2.4 & 3.3 & 3.0 & 3.8 & 1.8 & 2.8 & 0.725^{\mathrm{a}}\end{array}$

Frequent presence of the child in the kitchen during food cooking (\%)

$\begin{array}{llllllll}\text { Season I } & 19.2 & 14.0 & 14.5 & 17.6 & 20.3 & 17.1 & 0.271^{\mathrm{a}}\end{array}$

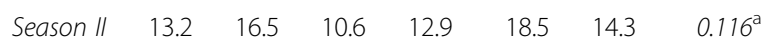

Cooking on the griddle/barbecue (\%)

$\begin{array}{llllllll}\text { Season I } & 62.4 & 56.2 & 56.2 & 59.5 & 48.0 & 56.5 & 0.027^{\mathrm{a}}\end{array}$

Season II $\quad 64.8 \quad 63.6 \quad 57.9 \quad 69.5^{*} \quad 50.2 \quad 61.2^{*} \quad<0.001^{\text {a }}$

Use of solvents for hobbies (\%)

$\begin{array}{llllllll}\text { Season I } & 2.0 & 4.5 & 4.7 & 5.7 & 3.1 & 4.0 & 0.264^{\mathrm{a}} \\ \text { Season II } & 1.6 & 3.7 & 3.4 & 3.3 & 4.4 & 3.3 & 0.508^{\mathrm{a}}\end{array}$

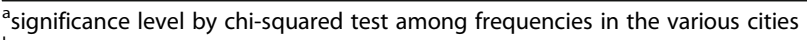
${ }^{b}$ significance level by one-way ANOVA among average values in the various cities

${ }^{*} p$-value $<0.05$ by chi-squared test between frequencies in the two seasons

the first season and $14.3 \%$ during the second. The practice of cooking food on the griddle increased significantly $(p<0.05)$ between the first $(56.5 \%)$ and second $(61.2 \%)$ seasons, with the highest frequency seen in BS (62.4\%) in season I and PI (69.5\%) in season II. Lastly, the use of solvents for hobbies was seen in 4.0 and 3.3\% of homes during the first and second seasons respectively, without appreciable differences between the cities or between survey periods.

The frequency of consumption of certain foods subject to particular cooking methods in the month before the survey was conducted (Table 6) varies between the two seasons and/or the five cities. Specifically, the consumption of foods cooked on the barbecue increased significantly between the first (30.1\%) and second (38.9\%) 
Table 6 Children who consumed foods subject to risky cooking methods in the month before the survey

\begin{tabular}{|c|c|c|c|c|c|c|c|}
\hline & BS & LE & PG & $\mathrm{Pl}$ & TO & mean & $P$-value ${ }^{a}$ \\
\hline \multicolumn{8}{|c|}{ Barbecued foods (wood/charcoal) (\%) } \\
\hline Season 1 & 25.3 & 37.2 & 39.6 & 31.9 & 16.3 & 30.1 & $<0.001$ \\
\hline Season $/ 1$ & $40.4^{*}$ & $44.6^{*}$ & 42.1 & $47.1^{*}$ & 20.3 & $38.9^{*}$ & $<0.001$ \\
\hline \multicolumn{8}{|c|}{ Foods cooked on the griddle (\%) } \\
\hline Season 1 & 71.1 & 58.7 & 54.0 & 58.1 & 57.3 & 60.0 & 0.002 \\
\hline Season 11 & 67.6 & 60.7 & 54.9 & 66.7 & 61.2 & 62.2 & 0.032 \\
\hline \multicolumn{8}{|c|}{ Fried foods (\%) } \\
\hline Season 1 & 75.5 & 81.4 & 77.0 & 69.0 & 80.6 & 76.9 & 0.017 \\
\hline Season II & 72.8 & 82.2 & 77.4 & $78.1^{*}$ & 79.7 & 78.0 & 0.141 \\
\hline \multicolumn{8}{|c|}{ Toasted bread (\%) } \\
\hline Season 1 & 56.2 & 45.5 & 58.3 & 49.0 & 48.5 & 51.6 & 0.022 \\
\hline Season $/ 1$ & 54.0 & 50.4 & 53.3 & 50.0 & 46.7 & 51.4 & 0.356 \\
\hline \multicolumn{8}{|c|}{ Smoked foods (\%) } \\
\hline Season 1 & 20.5 & 12.0 & 12.8 & 14.8 & 15.0 & 15.0 & 0.075 \\
\hline Season II & 23.6 & 19.8 & 12.8 & 18.6 & 16.3 & 18.3 & 0.033 \\
\hline \multicolumn{8}{|c|}{ Pizza cooked in a wood oven (\%) } \\
\hline Season 1 & 61.2 & 65.3 & 63.0 & 60.5 & 60.8 & 62.2 & 0.888 \\
\hline Season II & $69.6^{*}$ & 66.9 & 62.6 & $68.1^{*}$ & 64.3 & 66.3 & 0.487 \\
\hline
\end{tabular}

${ }^{\mathrm{a}}$ significance level by chi-squared test among frequencies in the various cities ${ }^{*} p$-value $<0.05$ by chi-squared test between frequencies in the two seasons

seasons, with the highest frequencies seen in PG (39.6\%) in winter and PI (47.1\%) in spring. In contrast, the children of TO had the lowest consumption in both sampling periods (16.3\% in season I and $20.3 \%$ in season II). Interestingly, the frequency of consumption of foods prepared with this method of cooking is overall higher among children with parents born outside of Italy (40.6\% in season I and $55.4 \%$ in season II) (not reported in table). In addition, significantly $(p<0.05)$ more frequent consumption of foods cooked on the griddle was recorded in BS in both the first (71.1\%) and second (67.7\%) seasons, of fried food in LE in the first season (81.4\%), of toasted bread in PG in the first season (58.3\%) and smoked foods in BS in the second season (23.6\%). Finally, frequency of consumption of pizza cooked in a wood oven was found significantly different $(p<0.05)$ between the two season in BS $(61.2 \%$ in season I and $69.6 \%$ in season II) and PI (60.5\% in season I and $68.1 \%$ in season II).

\section{Lifestyles and socio-economic level}

The frequencies of specific children's conditions in families with high or low socio-economic level are shown in Table 7. Exposure to passive smoking was significantly lower in families with parents' educational level $\geq 26$ combined years of schooling and when father had I or II occupation level as evidenced by the frequency of smoking mothers (16.2\% and 16.0 respectively) and fathers (21.9 and $19.5 \%)$, presence of smokers inside the dwelling (10.8 and 9.9\%) and staying of children in closed rooms with smokers (2.51 and 2.36\%). Also the frequency of obese children (14.4 and 13.9\%) as well as children that frequently stay in the kitchen during preparation of food (14.5 and 13.5\%) is lower in families with high cultural and economic background while the residence in areas with heavy traffic is associated only with lower occupational level (40.7\%). The frequency of children doing sports, including outdoor sports, is directly related to socio-economic level as opposed to frequency of children that play outdoor more than $1 \mathrm{~h}$ /day that it is greater in families with lower parent's educational level (59.7\%) and father's occupational level (57.4\%). Finally, children of parents with education level equal or higher than 26 combined years of schooling showed lower consumption of barbecued foods and higher consumption of toasted bread than children of parents with low educational level ( $<26$ combined years of schooling) while children living in families where father had high level of employment (I or II level) showed lower consumption of barbecued foods, fried foods and higher of toasted bread.

\section{Discussion}

Data on children's recruitment and questionnaire administration activities allowed to establish the level of participation to the study. Initially, 1767 parents $(56.2 \%$ of the 3144 invited) agreed to participate in the study. Although the various Research Units used the same recruitment protocol, the response rate varied across the cities involved, with the highest percentage of consenting parents in BS (67.8\%) and the lowest in LE (45.7\%). The reasons for this difference probably lie in the greater sensitivity to problems linked to atmospheric pollution (and the consequently greater awareness of the health risks) among citizens resident in areas in which pollution is tangible than persons who live in areas where pollution is less evident [27].

In addition, participation in our study was lower than other studies $[28,29]$ conducted on Italian children attending primary school in order to assess body size as a function of family, environmental and behavioral factors. In these studies the field activities were very discreet, being limited to recording the children's anthropometric data and distributing a questionnaire to the parents. In contrast, in the MAPEC study, the length of the questionnaire and the sampling of oral mucosa cells and saliva in order to detect early genotoxic effects in recruited children-despite being carried out with non-invasive methods that were readily tolerated by the childrenprobably induced many parents to not participate. 
Table 7 Association between behavioral factors and socio-economic levels of children's families

\begin{tabular}{|c|c|c|c|c|c|c|}
\hline & \multicolumn{3}{|c|}{ Parents' overall educational level } & \multicolumn{3}{|c|}{$\begin{array}{l}\text { Father's occupational } \\
\text { level }\end{array}$} \\
\hline & $\geq 26$ years of schooling & $<26$ years of schooling & $P$-value ${ }^{a}$ & | or || & III or IV & $P$-value ${ }^{a}$ \\
\hline Mother smoker (\%) & 16.2 & 27.5 & $<0.001$ & 16.0 & 24.5 & $<0.001$ \\
\hline Father smoker (\%) & 21.9 & 43.7 & $<0.001$ & 19.5 & 40.9 & $<0.001$ \\
\hline Presence of smokers inside the dwelling (\%) & 10.8 & 20.7 & $<0.001$ & 9.8 & 19.3 & $<0.001$ \\
\hline Staying in closed rooms with smokers (\%) & 2.51 & 5.04 & 0.003 & 2.36 & 4.50 & 0.006 \\
\hline Obese children (\%) & 14.4 & 18.5 & 0.017 & 13.9 & 18.0 & 0.009 \\
\hline $\begin{array}{l}\text { Frequent presence of the child in the kitchen during preparation } \\
\text { of food }(\%)\end{array}$ & 14.5 & 19.0 & 0.0105 & 13.5 & 19.4 & $<0.001$ \\
\hline Residence in areas with heavy traffic (\%) & 36.3 & 38.5 & 0.338 & 34.5 & 40.7 & 0.003 \\
\hline Sport ( $\geq 3$ times/week) (\%) & 50.0 & 35.9 & $<0.001$ & 49.2 & 41.4 & $<0.001$ \\
\hline Outdoor sports (\%) & 35.0 & 25.5 & $<0.001$ & 34.8 & 28.7 & 0.003 \\
\hline Swimming (indoor) (\%) & 6.42 & 7.15 & 0.594 & 5.76 & 8.00 & 0.044 \\
\hline Outdoor play (>1 h/day) (\%) & 48.7 & 59.7 & $<0.0001$ & 48.1 & 57.4 & $<0.001$ \\
\hline Consumption ${ }^{b}$ barbecued foods (\%) & 32.8 & 39.3 & 0.005 & 30.8 & 40.5 & $<0.001$ \\
\hline Consumption ${ }^{\mathrm{b}}$ of foods cooked on the griddle (\%) & 60.7 & 62.4 & 0.482 & 60.4 & 62.2 & 0.407 \\
\hline Consumption ${ }^{\mathrm{b}}$ of fried foods (\%) & 77.4 & 77.5 & 0.998 & 75.8 & 80.0 & 0.021 \\
\hline Consumption ${ }^{\mathrm{b}}$ of toasted bread (\%) & 53.4 & 46.3 & 0.003 & 54.0 & 47.5 & 0.003 \\
\hline Consumption ${ }^{b}$ of smoked foods (\%) & 17.2 & 15.3 & 0.320 & 16.5 & 17.0 & 0.766 \\
\hline Consumption ${ }^{\mathrm{b}}$ of pizza cooked in a wood oven (\%) & 65.1 & 61.8 & 0.149 & 65.4 & 62.4 & 0.151 \\
\hline
\end{tabular}

${ }^{a}$ significance level by chi-squared test

${ }^{b}$ in the month before the survey

The exclusion criteria and the requirement for followup further reduced the number of children to 1,164 . The composition of the final cohort was homogeneous in terms of gender, age and nation of birth. However, a selection bias could have been generated as detectable by the parents' level of education and rate of employment which appear slightly higher in our study than in general Italian population [28]. On the other hand, the percentage of foreign parents appears to be comparable, and the differences detected among the various cities seem to reflect data on the percentage of foreign citizens in the respective populations [16].

The BMI relative to study cohort also appear to be comparable with data from other studies [30] and confirm a higher proportion of overweight children in the central-southern regions, as better described in a specific publication on the association between weight status and lifestyles among the children enrolled in MAPEC_LIFE study [31]. This could be correlated also with poor eating habits and specifically with a low adherence to the Mediterranean diet especially in the cities of southern Italy [32].

Regarding the state of health and respiratory diseases in particular, a greater prevalence of bronchitis with production of catarrh was observed in the northern cities (BS and TO), probably associated with the colder climate or the greater levels of environmental pollution that have been widely documented in the Pianura Padana $[19,21,22]$. In this regard, several studies have shown an increase in many respiratory disorders, comprising persistent phlegm, in children in the more polluted areas [33-36]. The climates of the cities may also have influenced the frequency of physical exercise, with reference to open-air activities, which are less frequent in winter and in the colder cities.

Regarding the analysis of exposure factors linked to the home context, it emerged that the proportion of children living in areas with high traffic intensity is greatest in TO. However, the perceived intensity of traffic depends on both subjective factors and the specific areas where the children participating in the study live, which may not be representative of the city as a whole.

In contrast, the choice of fuel used for heating depends heavily on the environmental policies adopted in the various cities and on the utilities available to citizens heating their homes. Thus, in BS and TO, district heating, with "remote" production of heat, is the norm. This system serves to reduce the use of polluting fuels in urban areas with a high level of air pollution. In contrast, in LE, PG and PI, natural gas is preferred, and is also the main fuel used for cooking in all the cities participating in the study. Among the other types of heating, the use of wood-fired stoves is most frequent in PG while openhearth fires are most common in LE in winter and in 
TO in spring, probably following the switch-off of the centralized or remote systems while cold temperatures continue.

Exposure to passive smoking affects large part of the cohort: one child in three among those participating in the study has at least one smoking parent and one child in seven lives together with persons who smoke inside home although only $3.2 \%$ of the interviewees admitted the presence of their offspring together with a person who smokes in closed rooms. Moreover, data analysis reveals that the fathers were more likely to be smokers, and smoking parents were most frequent in TO.

On average one child in six among those participating in the study is usually present in the kitchen during the preparation of foods and is thus potentially exposed to genotoxic compounds such as acrylamide, heterocyclic amines, nitrosamines and polyaromatic hydrocarbons, which are formed during cooking and are released into air indoors in vapor and smoke [37]. Exposure to these contaminants was also significant in terms of the ingestion of foods subject to "risky" cooking methods (barbecued, griddled, fried, toasted, smoked) [38, 39]. In some cases there were significant differences between the two seasons or between the various cities, probably due to the different regional gastronomic traditions or the different size of the foreign component and consequently the different influence of "exotic" diets with respect to autochthonous food habits.

Data on the association between lifestyle and sociocultural level of the children's families show that education and employment of the parents strongly affect children's exposure to toxic contaminants in the home environment as passive smoking, cooking fumes and compounds originating from vehicular traffic as well as obesity, physical activity, ingestion of toxic substances arising from risky cooking methods. It is known that high occupational and educational levels entail access to goods and services (e.g., gymnasia and sports facilities, wellness centers, quality foods and restaurants, domestic help, etc.), which can create a protective environment in terms of various health problems [40-42]. In addition, dieting and health-promoting behaviors such as reducing smoking and high energy food and fat intake, a high level of exercise are more common in families of a higher socio-economic status [43, 44].

In summary, analysis of the data arising from the questionnaire filled in by the parents of the children participating in the MAPEC_LIFE study provides a sufficiently detailed picture of the composition of the cohort, the habits of the children and their potential exposure to certain environmental pollutants linked to the domestic context. Differences emerged with regard to the sampling period and the geographical areas. The latter could depend on different environmental, cultural and social aspects of the various cities involved in the study such as foreign citizens' rate, economic level of the population, local food habits, climatic aspects. These findings need to be taken into account when relating the frequency of biomarkers in the children's oral mucosa cells with the air concentration of genotoxic substances near the schools attended by the enrolled subjects.

Finally, it is important to point out that many of the children participating in the study were found to be exposed to pollution factors often attributable to illadvised behaviors on the part of the parents. This highlights the need to perform at various levels appropriate communication interventions concerning human health risks from air pollution and the measures to prevent them. As demonstrated in a pilot study within the MAPEC_LIFE project in order to evaluate the effectiveness of some educational tools regarding pollution [45], children are very sensitive to environmental issues and demonstrate to learn very quickly the concepts about the correct lifestyles to prevent adverse health effects from exposure to harmful substances. However, as pointed out in other studies [46], it is necessary above all to teach parents and the community about the environmental hazards for human health, including those linked to lifestyles, educating them about the special vulnerability of children and showing them how to protect their children by adopting practices that reduce the risks of exposure. Previous studies indicated that active communication with the pediatricians [47], the information through mass-media [46] and the involvement of parents in school education programs [48] could contribute to improve the perception of the risk associated with exposure to contaminants in the domestic environment and to adopt health-promoting behaviors. Improvement of the parent-child communication processes may also reduce individual risk factors [49].

\section{Limitations}

This study is not without its limitations. First, participation to the study was modest probably due to the length of the questionnaire or to biomonitoring analysis performed on recruited children. This may have generated an a priori selection bias, detectable by factors linked to the family context. The anthropometric data used in this work to calculate BMI were self-reported by the parents who compiled the questionnaires and were not measured in accordance with standardized methods. In addition, other factors (e.g., traffic near home or school, presence of the children in closed rooms with smokers) could be affected by subjective perception.

\section{Conclusions}

This study allowed to obtain information about exposure factors linked to the home context and lifestyle of 1,164 
children aged 6-8 years attending primary schools in five Italian cities with varying geographical, environmental, demographic and socio-economic characteristics.

Frequency of some factors appeared different in terms of the survey season (physical activity in the open air, the ways of cooking certain foods) and among the various cities (parents' level of education and rate of employment, sport, traffic near the home, type of heating, exposure to passive smoking, ways of cooking certain foods). The socio-economic level seems to affect the lifestyles of children enrolled in the study including those that could cause health effects. Many factors are linked to the geographical area and may depend on environmental, cultural and social aspects of the city of residence.

Information on outdoor and indoor environmental exposure and the lifestyles of participating children will be integrated with the results of environmental and biological monitoring and with other information acquired during the MAPEC_LIFE study in order to construct a global model of genotoxic risk that can be used to support environmental policies.

\section{Abbreviations}

BMI: Body mass index; BS: Brescia; IOTF: International Obesity Task Force; LE: Lecce; MAPEC: Monitoring Air Pollution Effects on Children for Supporting Public Health Policy; MN: Micronucleus; NW: Normal weight; OB: Obese; OW: Overweight; PG: Perugia; PI: Pisa; PM: Particulate matter; TO: Torino; UW: Underweight

\section{Acknowledgements}

Members of the MAPEC_LIFE Study Group: Francesca Serio, Mattia De Giorgi, Adele Idolo, Tiziano Verri (Department of Biological and Environmental Science and Technology, University of Salento, Lecce, Italy); Loredana Covolo, Francesco Donato, Andrea Festa, Rosa Maria Limina, llaria Zerbini (Department of Medical and Surgical Specialties, Radiological Sciences and Public Health, University of Brescia, Italy); Cristina Fatigoni, Sara Levorato, Silvano Monarca, Samuele Vannini, (Department of Pharmaceutical Sciences, University of Perugia, Italy); Gabriele Donzelli, Beatrice Bruni, Giacomo Palomba (Department of Biology, University of Pisa, Italy), Silvia Bonetta, Marta Gea, Giorgio Gilli, Cristina Pignata, Valeria Romanazzi (Department of Public Health and Pediatrics, University of Torino, Italy); Camilla Furia (Comune di Brescia, Italy), Roberta Codenotti, Paolo Colombi, Stefano Crottini, Laura Gaffurini, Licia Zagni (Centro Servizi Multisettoriale e Tecnologico - CSMT Gestione S.c.a.r.l., Italy).

\section{Funding}

The study was funded by the European Commission's Directorate-General Environment in the LIFE+ Programme for 2012, Environment Policy and Governance (grant number: LIFE12 ENV/TT/000614).

\section{Availability of data and materials}

The datasets during and/or analyzed during the current study are available from the corresponding author on reasonable request.

\section{Authors' contributions}

All authors made substantial contributions to the conception and design of the study and were involved in drafting and critically revising the manuscript in terms of intellectual content. In addition, FB conceived the study, performed the statistical analyses and interpreted the results. ADD was involved in study design and interpretation of results. TG contributed in the statistical analysis and interpretation of data. MG and GD were involved in interpretation of results. DF, MM, AC and ECa were involved in the study design and methodology. ECe, TSa, BC and TSc were involved in the development and administration of the questionnaire. CZ, MVi, MVe, SaB, SiB and $A B$ were involved in data management and contributed in statistical analysis. UG, the project leader and scientific coordinator of the consortium, devised the study design and methodology, and critically contributed in the interpretation of results. The Authors included in the MAPEC_LIFE study group were involved in collection and management of data. All authors have read and approved the manuscript, and have given final approval for submission.

\section{Competing interests}

The authors declare that they have no competing interests.

\section{Consent for publication}

Not applicable.

\section{Ethics approval and consent to participate}

The corresponding author explicitly states that any necessary ethics committee approval was secured for the study reported. Names and locations of the approving ethics committees are listed below: BS: Comitato Etico Provinciale, Provincia di Brescia, c/o Spedali Civili, Piazzale Spedali Civili 1, 25123 Brescia. LE: Comitato Etico, ASL Lecce, Via Miglietta 5, 73100 Lecce. PG: Comitato Universitario di Bioetica, Università degli Studi di Perugia, Via Gambuli, 06132 Perugia. Pl: Comitato Etico Pediatrico Regionale c/o Azienda Ospedaliera Universitaria Meyer, Viale Pieraccini 24, 50139 Firenze. TO: Comitato di Bioetica di Ateneo, Università degli Studi di Torino, Via Bogino 9, 10123 Torino. The corresponding author also state that the participation in the study was voluntary. The subjects were admitted after the children's parents had received an adequate and understandable explanation about the intent of the study, the possible results, their meaning, and signed the informed consent form.

\section{Author details}

'Department of Biological and Environmental Science and Technology, University of Salento, Via Prov.le Lecce-Monteroni, 73100 Lecce, Italy. ${ }^{2}$ Department of Medical and Surgical Specialties, Radiological Sciences and Public Health, University of Brescia, Brescia, Italy. ${ }^{3}$ Department of Pharmaceutical Sciences, University of Perugia, Perugia, Italy. ${ }^{4}$ Department of Biology, University of Pisa, Pisa, Italy. ${ }^{5}$ Department of Translational Research, N.T.M.S., University of Pisa, Pisa, Italy. ${ }^{6}$ Department of Public Health and Pediatrics, University of Torino, Torino, Italy. ${ }^{7}$ Comune di Brescia, Brescia, Italy. ${ }^{8}$ Centro Servizi Multisettoriale e Tecnologico - CSMT Gestione S.c.a.r.l., Brescia, Italy.

Received: 23 July 2016 Accepted: 23 February 2017

Published online: 07 March 2017

\section{References}

1. World Health Organization. Health Promotion Glossary. Geneva: WHO; 1998.

2. World Health Organization. The WHO cross-national study of health behavior in school-aged children from 35 countries: findings from 20012002. J Sch Health. 2004:74:204-6.

3. Danaei G, Ding EL, Mozaffarian D, Taylor B, Rehm J, Murray CJ, et al. The preventable causes of death in the United States: comparative risk assessment of dietary, lifestyle, and metabolic risk factors. PLoS Med. 2009;6:e1000058.

4. Ding D, Rogers K, van der Ploeg H, Stamatakis E, Bauman AE. Traditional and emerging lifestyle risk behaviors and all-cause mortality in middle-aged and older adults: evidence from a large population-based Australian Cohort. PLoS Med. 2015;12(12):e1001917.

5. Sanci LA, Coffey CM, Veit FC, Carr-Gregg M, Patton GC, Day N, Bowes G. Evaluation of the effectiveness of an educational intervention for general practitioners in adolescent health care: randomized controlled trial. BMJ. 2000;320(7229):224-9

6. Wainwright $\mathrm{P}$, Thomas J, Jones $\mathrm{M}$. Health promotion and the role of the school nurse: A systematic review. J Adv Nurs. 2000;32(5):1083-91.

7. Wang D, Ou CQ, Chen MY, Duan N. Health-promoting lifestyles of university students in Mainland China. BMC Public Health. 2009:9:379.

8. Currie C, Zanotti C, Morgan A, Currie D, de Looze M, Roberts C, et al. Social determinants of health and well-being among young people. Health Behaviour in School-aged Children (HBSC) study: international report from 
the 2009/2010 survey, Health Policy for Children and Adolescents, No. 6 Copenhagen: WHO Regional Office for Europe; 2012

9. Reilly JJ, Methven E, McDowell ZC, Hacking B, Alexander D, Steward L, et al. Health consequences of obesity. Arch Dis Child. 2003;88:748-52.

10. Ebbeling CB, Pawlak DB, Ludwig DS. Childhood obesity: public-health crisis, common sense cure. Lancet. 2002;360:473-82.

11. Wang G, Dietz WH. Economic Burden of Obesity in Youths Aged 6 to 17 Years: 1979-1999. Pediatrics. 2002;109:81-6.

12. Ahmad QI, Ahmad CB, Ahmad SM. Childhood Obesity. Indian J Endocrinol Metab. 2010;14:19-25.

13. Scarborough $P$, Bhatnagar $P$, Wickramasinghe KK, Allender S, Foster $C$, Rayner M. The economic burden of ill health due to diet, physical inactivity, smoking, alcohol and obesity in the UK: an update to 2006-07 NHS costs. J Public Health. 2011;33:527-35.

14. Feretti D, Ceretti E, De Donno A, Moretti M, Carducci A, Bonetta S, et al. Monitoring air pollution effects on children for supporting public health policy: the protocol of the prospective cohort MAPEC study. BMJ Open. 2014;4(9):e006096. doi:10.1136/bmjopen-2014-006096.

15. Zani C, Donato F, Grioni S, Viola GCV, Ceretti E, Feretti D, et al. Feasibility and reliability of a questionnaire for evaluation of the exposure to indoor and outdoor air pollutants, diet and physical activity in 6-8-year-old children. Ann lg. 2015;27(4):646-56. doi:10.7416/ai.2015.2056.

16. Italian National Institute of Statistics (ISTAT). www.istat.it. Accessed 10 June 2016.

17. Peano A. Torino ieri, oggi, domani: una visione di sintesi. Macramè. 2007;1:13-21.

18. Finardi S, De Maria R, D'Allura A, Cascone C, Calori G, Lollobrigida F. A deterministic air quality forecasting system for Torino urban area, Italy. Environ Model Softw. 2008;23:344-55.

19. Eeftens M, Beelen R, de Hoogh K, Bellander T, Cesaroni G, Cirach M, et al. Development of Land Use Regression models for $\mathrm{PM}_{2.5}, \mathrm{PM}_{2.5}$ absorbance, $\mathrm{PM}_{10}$ and $\mathrm{PM}_{\text {coarse }}$ in 20 European study areas; results of the ESCAPE project. Environ Sci Technol. 2012:46(20):11195-205.

20. Istituto Superiore per la Protezione e la Ricerca Ambientale (ISPRA). Sistema nazionale per la raccolta, l'elaborazione e la diffusione di dati Climatici di Interesse Ambientale. 2016 http://www.scia.isprambiente.it. Accessed 10 June 2016.

21. Monarca S, Crebelli R, Feretti D, Zanardini A, Fuselli S, Filini L, et al. Mutagens and carcinogens in size-classified air particulates of a northern Italian town. Sci Total Environ. 1997;205(2-3):137-44.

22. European Environment Agency. Air Quality in Europe - 2015 report. EEA Report. 2015;5:1-57. doi:10.2800/62459.

23. Costantini EAC, Fantappiè M, L'Abate G. Climate and pedoclimate of Italy. In: Costantini EAC, Dazzi C, (Eds). Desoils of Italy. Springer Netherlands 2013; 19-37. DOI: 10.1007/978-94-007-5642-7_2.

24. RUR-CENSIT. Municipium. Le città italiane in Movimento: Roma; 2004.

25. Cole TJ, Bellizzi MC, Flegal KM, Dietz WH. Establishing a standard definition for child overweight and obesity worldwide: international survey. BMJ. 2000; 320:1240-3.

26. Cole TJ, Flegal KM, Nicholls D, Jackson AA. Body mass index cut offs to define thinnes in children and adolescents: international survey. BMJ. 2007:335:194.

27. Bickerstaff K. Risk perception research: socio-cultural perspectives on the public experience of air pollution. Environ Int. 2004;30(6):827-40.

28. Buoncristiano M, Bucciarelli M, Nardone P, Lauria L, Spinelli A. Caratteristiche della popolazione. In: Nardone P, Spinelli A, Buoncristiano M, Lauria L, Pizzi E, Andreozzi S, Galeone D, editors. II Sistema di sorveglianza OKkio alla SALUTE: risultati 2014. Roma: Istituto Superiore di Sanità; 2016. p. 9-12.

29. Censi L, D'Addesa D, Martone D, Galfo M, Bevilacqua N, Roccaldo R, et al. Articolazione dello Studio ZOOM8. In: Censi L, D’Addesa D, Galeone D, Andreozzi S, Spinelli A. Studio ZOOM8: I'alimentazione e l'attività fisica dei bambini della scuola primaria. Rapporti ISTISAN 12/42. Roma: Istituto Superiore di Sanità; 2012. p. 5-16.

30. Nardone P, Spinelli A, Lauria L, Buoncristiano M, Bucciarelli M. Andreozzi S and Gruppo OKkio alla SALUTE 2008-09, 2010, 2012 e 2014. Lo stato ponderale dei bambini. In: Nardone P, Spinelli A, Buoncristiano M, Lauria L, Pizzi E, Andreozzi S, Galeone D, editors. II Sistema di sorveglianza OKkio alla SALUTE: risultati 2014. Roma: Istituto Superiore di Sanità; 2016. p. 13-8.

31. Grassi T, De Donno A, Bagordo F, Serio F, Piscitelli P, Ceretti E, et al. SocioEconomic and Environmental Factors Associated with Overweight and Obesity in Children Aged 6-8 Years Living in Five Italian Cities (the MAPEC LIFE Cohort). Int J Environ Res Public Health. 2016;13:1002. doi:10.3390/ ijerph13101002
32. Zani C, Ceretti E, Grioni S, Viola GCV, Donato F, Feretti D, et al. Are 6-8 year old Italian children moving away from the Mediterranean diet? Ann Ig. 2016;28(5):339-48. doi:10.7416/ai.2016.2114.

33. Sunyer J. Urban air pollution and chronic obstructive pulmonary disease: a review. Eur Respir J. 2001;17(5):1024-33.

34. Pan G, Zhang S, Feng Y, Takahashi K, Kagawa J, Yu L, et al. Air pollution and children's respiratory symptoms in six cities of Northern China. Respir Med. 2010;104(12):1903-11.

35. Ripabelli G, Tamburro M, Sammarco ML, de Laurentiis G, Bianco A. Asthma prevalence and risk factors among children and adolescents living around an industrial area: a cross-sectional study. BMC Public Health. 2013:13:1038.

36. Sram RJ, Binkova B, Dostal M, Merkerova-Dostalova M, Libalova H, Milcova A, et al. Health impact of air pollution to children. Int J Hyg Envir Heal. 2013; 216(5):533-40.

37. Wang J, Luo X, Xu B, Wei J, Zhang Z, Zhu H. Elevated Oxidative Damage in Kitchen Workers in Chinese Restaurants. J Occup Health. 2011;53:327-33.

38. Jägerstad M, Skog K. Genotoxicity of heat-processed foods. Mutat Res. 2005; 574(1-2):156-72.

39. Katic J, Cemeli E, Baumgartner A, Laubenthal J, Bassano I, Stølevik SB, et al. Evaluation of the genotoxicity of 10 selected dietary/environmental compounds with the in vitro micronucleus cytokinesis-block assay in an interlaboratory comparison. Food Chem Toxicol. 2010:48(10):2612-23.

40. Kleiser C, Schaffrath Rosario A, Mensink GBM, Prinz-Langenohl R, Kurth BM. Potential determinants of obesity among children and adolescents in Germany: results from the cross-sectional KiGGS study. BMC Public Health. 2009;9:46.

41. Coll JL, del Mar Bibiloni M, Salas R, Pons A, Tur JA. The prevalence of excessive weight in Balearic Islands' young and middle-aged women and its association with social and socioeconomic factors: a ten-year trend (2000-2010). BMC Public Health. 2015;15:837.

42. Lissner L, Wijnhoven TMA, Mehlig K, Sjöberg A, Kunesova M, Yngve A, et al. Socioeconomic inequalities in childhood overweight: heterogeneity across five countries in the WHO European Childhood Obesity Surveillance Initiative (COSI-2008). Int J Obesity. 2016:40:796-802.

43. Lin BH, Huang CL, French SA. Factors associated with women's and children's body mass indices by income status. Int J Obesity. 2004;28:536-42.

44. Lamerz A, Kuepper-Nybelen J, Wehle C, Bruning N, Trost-Brinkhues G, Brenner $\mathrm{H}$, et al. Social class, parental education, and obesity prevalence in a study of six-year-old children in Germany. Int J Obesity. 2005;29:373-80.

45. Carducci A, Casini B, Donzelli G, Verani M, Bruni B, Ceretti E, et al. Improving awareness of health hazards associated with air pollution in primary school children: design and test of didactic tools. Appl Environ Educ Commun. 2016;15(3):247-60. doi:10.1080/1533015X.2016.1181017.

46. Dziubanek G, Marchwińska-Wyrwał E, Piekut A, Hajok I, Bilewicz-Wyrozumska T, Kuraszewska B. Environmental Risks Perception-A Study of the awareness of families to threats in areas with increased health disorders in children. Ann Agric Environ Med. 2013;20(3):555-8.

47. Galvez MP, Peters R, Graber N, Forman J. Effective risk communication in children's environmental health: lessons learned from 9/11. Pediatr Clin North Am. 2007;54(1):33-46.

48. Golley RK, Hendrie GA, Slater A, Corsini N. Interventions that involve parents to improve children's weight-related nutrition intake and activity patternswhat nutrition and activity targets and behaviour change techniques are associated with intervention effectiveness? Obes Rev. 2011;12:114-30.

49. Norton DE, Froelicher ES, Waters CM, Carrieri-Kohlman V. Parental influence on models of primary prevention of cardiovascular disease in children. Eur J Cardiovasc Nurs. 2003;2(4):311-22.

\section{Submit your next manuscript to BioMed Central and we will help you at every step:}

- We accept pre-submission inquiries

- Our selector tool helps you to find the most relevant journal

- We provide round the clock customer support

- Convenient online submission

- Thorough peer review

- Inclusion in PubMed and all major indexing services

- Maximum visibility for your research

Submit your manuscript at www.biomedcentral.com/submit 